\title{
THE ROLE OF LEADERSHIP STYLES IN ACHIEVING THE ADMINISTRATIVE CREATIVITY OF THE MINISTRY OF EDUCATION - AN ANALYTICAL STUDY
}

\author{
Researcher Areech Nazar Abdulrahman \\ Ministry of Education - Administrative Affairs Directorate - Micro-Film Division
}

DOI: $10.37648 /$ ijrssh.v10i03.022

Received: 10 ${ }^{\text {th }}$ June, 2020; Accepted: 01 ${ }^{\text {st }}$ July, 2020; Published: 21st July,2020

\section{ABSTRACT}

The research dealt with the topic (The effect of leadership patterns in achieving administrative creativity, field research in the Ministry of Education) and derives the importance of research not only in its intellectual and philosophical framework, but also extends to the applied aspects in the Ministry of Education, the researcher still intends to measure the impact of leadership patterns represented by (the exploitative and authoritarian leadership, Parental, authoritarian leadership, participatory leadership, and democratic leadership) in the educational organization. This research seeks to design a hypothetical model that explains the influencing relationships between leadership patterns and administrative creativity in the researched organization. The research problem has raised the following question: Which patterns A leader in the Ministry of Education influences the achievement of managerial creativity. The research was applied at the Ministry of Education and the questionnaire was used as a main tool to collect data and information as well as personal interviews. The main and subsidiary hypotheses of the research were tested, in order to process data and information based on the SPSS program to obtain the statistical methods represented by (the arithmetic mean, the standard deviation, the Pearson correlation coefficient, the simple regression coefficient, and the researcher reached a set of conclusions, among them: The organization tends to follow The practices of participating leadership style and the style of democratic leadership when dealing with subordinates within the organization focuses on the collective goal and the work of one team, seeks to raise levels of performance and support efforts for continuous improvement, organizational development and total quality management that are common Important and essential in achieving administrative creativity, the researcher has set a set of recommendations, the most important of which are: the need for the Ministry of Education to pay attention to administrative creativity and its accreditation within the University Performance Division with (strategic planning, external focus - information and analysis, faculty / staff, operations effectiveness) and the development of its practices within the structure The organizational structure of the educational institution to direct and rationalize its human, financial, material and informational resources, as well as the need for the Ministry of Education to pay attention to the two modes of leadership (participation and democracy) and encourage, promote and develop them among decision makers in them, to raise the level of their responsibilities towards and Aivhm and give them independence and self-control, and over the level of participation in the educational institution to carry out these functions, which encourages generally good administrative behavior of the leadership they have.

Key Word : administrative creativity - role of leadership - leadership styles 


\section{INTRODUCTION}

The environment of contemporary organizations faces major challenges represented by multiple phenomena, the most important of which are the manifestations of globalization and the intensification of local and global competition, knowledge and cultural diversity, the multiplicity of sources and quality of human resources required and strategic directions as well as the speed of technical and information development and means of communication, and these challenges have become a great pressure on organizations in general, And motivates them to make transformations that are not simple in how they are matched by the change in the quality of their operations, whether they are internally, or related to their external environment or the market, so that they can adapt and adapt to everything that is new to materialize Principles of good governance. Instead of stereotypical and traditional practices in order to achieve administrative creativity, depending on the embodiment of leadership styles practices inside and outside the organization, up to the administrative creativity to confront these variables and current and future challenges.

Also, the success of any organization was not caused by the low costs and the quality of the products of these organizations, but also came in a large and important part in it through the possession of these organizations by administrative leaders who exercise leadership styles that depend on them to direct subordinates in order to achieve the set goals. Accordingly, the recent trend in competition indicates that competition between organizations today is based on the leadership styles practiced by leaders in those organizations, according to that. Leadership patterns are an essential source of building the administrative creativity of the organization. Administrative creativity is the main and driving assistant of business organizations in practicing their work. Being one of the strengths that it has and that helps it in enhancing its competitive advantage, so the researcher requested to describe the variables of leadership patterns and administrative creativity and diagnose them, as well as to analyze the relationship and influence those variables and provide recommendations and suggestions to the organization In the future, the idea of the current research has evolved to address contemporary issues that have a large and distinct role in the performance of organizations efficiently and effectively. This research came to take upon itself the testing of these variables in the education sector, which is in urgent need of such research, and the pooling of efforts And its focus on the most important aspects, which occupies an advanced position and as an essential factor in the success of organizations, and the achievement of administrative creativity.

\section{THE FIRST TOPIC: RESEARCH METHODOLOGY}

\section{First: The research problem}

Modern technologies and the availability of financial and financial capabilities, on their own, are no longer sufficient to achieve administrative creativity despite their importance in light of the dynamic dynamic environment variables, and educational organizations require seeking to prepare intermediate technical staffs and with high and multiple levels of qualification capable of dealing with modern technologies that meet the needs of an environment the work. Building a strong and effective administration and preparing leaders with modern innovative capabilities with a close vision capable of influencing and influencing the environment and dealing with them at a high level of capabilities and capabilities and making better use of them to align everyone's goals (individual, employees, management, society, environment) to achieve administrative creativity. Through the researcher's briefing on previous research and studies, the research problem revolves around measuring the impact of leadership patterns in achieving administrative creativity in the Ministry of Education. Leaders should also use the appropriate leadership styles for a distinguished, successful and efficient performance to achieve the mission of educational institutions and their goals through processes (strategic planning, external focus, information and analysis, faculty / staff and focus on work sites, and process effectiveness), which seek to Exercise. Despite the limited use of leadership styles appropriate to the circumstances of individuals in the Ministry of Education does not lead to achieving the desired goals.

Based on the foregoing, the research problem can be framed through the following questions:

A- What is the nature of leadership styles in the Ministry of Education?

B- What are the relationship and influence between leadership styles in achieving administrative creativity in the Ministry of Education?

C- What is the extent of the influence of each leadership style in achieving administrative creativity in the Ministry of Education? 
D- Which leadership styles are most influential in achieving administrative creativity in the Ministry of Education?

\section{Second: The importance of research}

This research acquires its cognitive importance, as it represents one of the intellectual and descriptive contributions and provides an additional reference specialized in the sciences of public administration and business administration, it provides the Arab library in general and the Iraqi library in particular in the subjects of leadership patterns and administrative creativity, and also contributes to increasing the progress and development of scientific research, and in raising the interest of researchers And academics and practitioners in this field. Leading patterns are embodied.

\section{Third: Research objectives}

In the light of the research problem and its importance, this research seeks to achieve the following goals:

1- Learn about the prevailing leadership patterns in the Ministry of Education.

2- Knowing the level of administrative creativity in the Ministry of Education.

3- Measuring the influencing relationships between leadership styles and administrative creativity in the Ministry of Education.

4- Designing a hypothetical model that explains the relationships of influence and influence between leadership patterns and administrative creativity in the Ministry of Education that simulates the problem of research.

5- Setting the conclusions and recommendations for this applied research as a starting point for future studies and research, to contribute to the development of the research organization, its distinction and its local prosperity.

Fourth: Research hypotheses

1. The first main hypothesis: There is a correlation between leadership styles and administrative creativity in the Ministry of Education.

The following main hypotheses have emerged from the following hypothesis:

A- There is a correlation between the exploitative and exploitative leadership used in the Ministry of Education and administrative creativity.

B- There is a correlation between the authoritarian and patriarchal leadership used in the Ministry of Education and administrative creativity.

C- There is a correlation between the participating leadership used in the Ministry of Education and administrative creativity.
D- There is a correlation between the democratic leadership used in the Ministry of Education and administrative creativity.

2. There is an effective relationship with significant statistical significance between the leadership patterns represented by leadership (authoritarian, patriarchal, participatory and democratic) in the Ministry of Education and Administrative Innovation.

The following main hypotheses have emerged from the following hypothesis:

A- There is an influence relationship of significant statistical significance between the exploitative and authoritarian leadership used in the Ministry of Education and administrative creativity.

B- There is a significant statistically significant influence relationship between the authoritarian and patriarchal leadership used in the Ministry of Education and administrative creativity.

C- There is a significant statistically significant effect relationship between the participating leadership used in the Ministry of Education and Administrative Creativity.

D- There is an effective relationship with statistically significant significance between the democratic leadership used in the Ministry of Education and administrative creativity.

\section{Fifth: Research Methodology}

The researcher adopted (the descriptive analytical method), which does not stop at the point of collecting information to describe the phenomenon, but rather analyzes it and reveals the relationships between its dimensions. And to complete the research theoretically and in the field and to reach the results, analyze them, discuss them and test their hypotheses, to reach the applied indications for them (conclusions and recommendations).

Sixth: Description and sample of the research community:

The Ministry of Education was chosen to form a community to test the hypotheses and study plan, due to the following reasons:

1 - It is considered one of the strategic institutions in the country.

2- Its active role in the civilizational construction of society.

3- Her leadership of science policies in the country.

4- The importance of the strategic objectives placed upon it.

An intentional sample was taken for the study, which is represented by general managers, their assistants, working experts, holders of higher degrees in the 
Ministry of Education, section managers, their assistants, and people's directors, being scientific and strategic leaders of their ministries. Workers in the aforementioned place and the researcher found good cooperation from the sample members.

\section{Seventh: The stability of the questionnaire}

For the purpose of verifying the consistency of the current research tool, the researcher adopted a consistency method that means the internal consistency of the paragraphs, which depends on finding the relationship between each paragraph and other paragraphs and for all paragraphs of the tool, and we use for this purpose the Vakronbach equation. Based on the foregoing, the coefficient of persistence in the Vakronbach method, which amounted to (0.896) is considered an acceptable percentage, as the acceptable percentage in such research is (70 or more), and thus the paragraphs that will be adopted in the final questionnaire (55) become a paragraph within the dimensions of the variables.

Eighth: Analysis of personal variables (demographic)

Table (1) characteristics of the research community

\begin{tabular}{|c|c|c|c|c|}
\hline No & Variables & Class distribution & Number & percentage \\
\hline \multirow{3}{*}{1} & \multirow{3}{*}{ Gender } & Male & 23 & $46.0 \%$ \\
\hline & & Female & 27 & $\% 54.0$ \\
\hline & & Total & 50 & $100 \%$ \\
\hline \multirow{5}{*}{2} & \multirow{5}{*}{ age categories } & 30 years and under & 13 & $26.0 \%$ \\
\hline & & 31-40 years old & 23 & $46.0 \%$ \\
\hline & & 41-50 years old & 8 & $16.0 \%$ \\
\hline & & 51-60 years old & 6 & $12.0 \%$ \\
\hline & & Total & 50 & $100 \%$ \\
\hline \multirow{6}{*}{3} & \multirow{6}{*}{$\begin{array}{l}\text { Academic } \\
\text { achievement }\end{array}$} & diploma & 5 & $10.0 \%$ \\
\hline & & $\mathbf{B A}$ & 37 & $74.0 \%$ \\
\hline & & Higher Diploma & 2 & $4.0 \%$ \\
\hline & & master & 6 & $12.0 \%$ \\
\hline & & Ph.D. & - & - \\
\hline & & Total & 50 & $100 \%$ \\
\hline \multirow{6}{*}{4} & \multirow{6}{*}{ Career Title } & Division Director & 24 & $48.0 \%$ \\
\hline & & $\begin{array}{l}\text { Director of the } \\
\text { Department }\end{array}$ & 4 & $8.0 \%$ \\
\hline & & Director general & 1 & $2.0 \%$ \\
\hline & & Associate Director & 3 & $6.0 \%$ \\
\hline & & Officer & 18 & $36.0 \%$ \\
\hline & & Total & 50 & $\% 100$ \\
\hline \multirow{5}{*}{5} & \multirow{5}{*}{ Career age } & $1-5$ years & 5 & $\% 10.0$ \\
\hline & & 6-10 years & 13 & $\% 26.0$ \\
\hline & & 11-15 years & 15 & \%30.0 \\
\hline & & 16 years and over & 17 & $\% 34.0$ \\
\hline & & Total & 50 & $\% 100$ \\
\hline
\end{tabular}

Characteristics of the research community (Ministry of Education)

It is evident from Table (1) above:

1. The percentage of males was $(46.0 \%)$, with a frequency of (23) of the total research community, while the percentage of females $(54.0 \%)$ and with a frequency of (27) of the total surveyed population, as this ratio indicates an increase in the percentage of females in the ministry compared to males and the reason is due In that, males and females do not have the same orientation in learning and behavior, which appears in the different goals and desires that they seek to reach.

2. The percentage of the age group that ranges between (31-40 years) has reached the highest percentage (46\%) of the research community, with a frequency of (23), followed by the age group that is less than (30 years) and with a frequency of (13) and a rate of (26\%), 
While the age group (41-50 years) got the percentage $(16 \%)$ and by repeating (8), while the age group (51-60 years) got the lowest percentage (12\%) and by repeating (6) as the results indicate that the research community owns Experiences and knowledge in their field of expertise, as well as their acquisition of these experiences due to the long period of time and the job context in the field of experience from the functional side of their descendants, which was reflected in their administrative and technical maturity and their ability to make decisions, except $\mathrm{N}$ ratios indicate the need to renew the ministry under study blood through election or appointment.

3. While the highest educational attainment percentage for the research community was for a bachelor's degree with a rate of (74\%) and with a frequency of (37), while the master's degree category obtained the second order with a rate of (12\%) and with a frequency of (6), while the diploma of the higher diploma got the lowest rate (4) \%) Repeatedly (2), and the diploma category obtained a ratio of $(10 \%)$ and by repeating (5). The results also show that there is no doctorate degree in the research sample, as the researcher notes that the ministry is distinguished by obtaining university degrees, which is reflected in their understanding of the researcher's work Express assistance and quick response in providing information, as well as their interest in their work and organizational maturity in the field of management In light of the search variables and its dimensions.

4. It appears from the above table that $48 \%$ of the research sample was of the degree of (Division Director), and the degree of (Department Director) got $8 \%$ of the sample surveyed. As for the degree of (General Manager), it got the least 2\% of the total sample of the research The same applies to the degree of (Associate Director), which is 6\%.

Of the total sample, as for the degree of (employees), it obtained $36.0 \%$ of the sample.

5. While the research community was distributed according to the employment age, as the service category (16 years or more) obtained the highest percentage of $(34 \%)$ and iterated (17), while the service category whose service ranged (11-15) got
(30\%) and repeatedly (15) As for the category of service that ranges between (6-10) (26\%) and with frequency (13), and finally, the service category (1-5) got the lowest percentage $(10 \%)$ and by repeating (5) and this indicates that the category The large population in the sample is young and is more eager to aspire to learn and gain knowledge, experience and skills.

\section{THE SECOND TOPIC: LITERATURE REVIEW / LEADERSHIP STYLES}

\section{First: the concept of leadership styles}

There are multiple names that were involved in defining the concept of (leadership styles), some call it (leadership styles) (Al-Qaisi, 2009: 49), while others call it (leadership types), and also (leadership models) and (leadership forms) and this diversity in the designation Although it is formal, in reality it reflects a diverse reality with a wide horizon of ideas, formulas and dimensions within the framework of this concept, and these leadership patterns determine the situational factors that relate to the leaders 'own philosophy, their personalities and their experiences on the one hand and the nature of the groups they lead and the scientific level of their individuals and the pattern of their personalities and the nature of the work environment on the one hand Others. A pattern is generally defined as "the way in which things are accomplished or done or is the way in which an individual deals, for each individual has his own way of working and dealing and has his own style or style that distinguishes him from others" (Durra et al., 1994: 297). The researcher will classify the definitions of leadership styles into three categories based on the definitions of writers and researchers, as there are those who focused on their definitions on the behavior and behavior of the leader in their interpretation of leadership patterns, while other researchers focused on the skills or attributes of a leader in their interpretation of leadership patterns, as other researchers focused on Their interpretation of leadership styles over the leader's activity, as shown in Table (2). 
Table (2) Classifying the definitions of leadership styles according to the opinions and opinions of a number of researchers and writers

\begin{tabular}{|c|c|c|c|}
\hline No & The standard & researcher & the definition \\
\hline 1 & $\begin{array}{l}\text { The conduct and } \\
\text { behavior of the } \\
\text { leader }\end{array}$ & (Al Qaisi, 2009: 49) & $\begin{array}{l}\text { Repetitive behavior demonstrated by the leader in } \\
\text { certain situations. }\end{array}$ \\
\hline 2 & & $\begin{array}{l}\text { (Wasila , Abdel Nasser, } \\
\text { 2009: 4) }\end{array}$ & $\begin{array}{l}\text { Repetitive behavior by the leader when dealing } \\
\text { with others so that he can win their cooperation and } \\
\text { persuade them to achieve goals, which is a pattern } \\
\text { that distinguishes him from the rest of the leaders. }\end{array}$ \\
\hline 3 & & (Haider, 2009: 64) & $\begin{array}{l}\text { The conduct of a leader is as seen by others he } \\
\text { works with, and not as his owner sees it. }\end{array}$ \\
\hline 4 & & (Khasawneh, 2011: 94) & $\begin{array}{l}\text { The behavior shown by the leader in his exercise of } \\
\text { power and influence over his subordinates in the } \\
\text { organization, which may be reflected in the extent } \\
\text { of the interaction of subordinates and their response } \\
\text { to that leadership style and the extent of performing } \\
\text { administrative operations }\end{array}$ \\
\hline 5 & (Rogers, 2012: 48) & & $\begin{array}{l}\text { The behavior of the leader in his interactions and } \\
\text { behaviors with the followers There are two types of } \\
\text { general behaviors: mission behaviors and } \\
\text { relationship behaviors, mission behaviors help in } \\
\text { achieving a goal such as helping group members } \\
\text { achieve their goals, while relationship behaviors } \\
\text { help subordinates to feel comfortable with } \\
\text { each other, with themselves, and in Particular } \\
\text { position. }\end{array}$ \\
\hline 6 & $\begin{array}{l}\text { The skills or } \\
\text { attributes of a } \\
\text { leader }\end{array}$ & (Al-Taie, 2007: 50) & $\begin{array}{l}\text { A set of attributes and skills that a leader possesses } \\
\text { or possesses. }\end{array}$ \\
\hline 7 & & (Bosiok, 2013: 65) & $\begin{array}{l}\text { A mixture of traits, skills, and behaviors that } \\
\text { leaders use when they interact with subordinates. }\end{array}$ \\
\hline 8 & Leader activity & (Al Sharif, 2004: 28) & $\begin{array}{l}\text { The activity carried out by the leader within the } \\
\text { organization to influence the behavior of } \\
\text { employees and make them cooperate with him to } \\
\text { achieve the desired goals by the organization on the } \\
\text { one hand and by those working with him on the } \\
\text { other hand. }\end{array}$ \\
\hline 9 & & (Al-Aibani, 2011: 30) & $\begin{array}{l}\text { Organized humanitarian activity aimed at achieving } \\
\text { the goals of the organization, by collecting and } \\
\text { unifying all available resources and putting them } \\
\text { into optimal use. }\end{array}$ \\
\hline
\end{tabular}

Source: Preparing the researcher based on the opinions of researchers and the book

Through what has been presented, the researcher agrees with the first classification that focuses on behavior and accordingly, the leadership style can be defined from the researcher's point of view and according to the main purpose of this research and its directions as "the behavior followed by the leader in dealing with subordinates, which drives them to work and achieve the required goals."

\section{Second: Leadership Styles Classifications}

It is difficult to find a single pattern for a leader, because patterns differ from one culture to another, and this is what resulted in the difference of researchers in categorizing several criteria for leadership styles. 
a. Looking at the leadership in terms of the source of authority the leader relies on to direct the group.

B. Looking at the leadership in terms of the leader's style and practice of influencing his staff and their method.

Other researchers believe that there are three criteria that are relied upon to classify leadership styles (the characteristics of leaders, the characteristics of subordinates, the organization's environment). This is what he emphasized (Al-Sharif, 2004: 81), as he mentioned that there are three basic factors that the leader takes into consideration when choosing The appropriate leadership style which is (factors specific to the leader, factors specific to subordinates, factors specific to the situation or environment).

\section{THE THIRD TOPIC / ADMINISTRATIVE CREATIVITY}

First: The concept of administrative creativity:

The concept of administrative creativity carries multiple implications and interpretations. Every researcher or scientist explains this term by referring to one or more distinct factors for creativity such as the characteristics or personality traits and mental skills of creative workers along with the organizational characteristics or variables that distinguish each organization from others that affect its role. In the level and type of creativity in it.

Some scholars and researchers have tried to provide various definitions about administrative creativity according to their differing views on the subject and table (3) offers a side of these definitions.

Table (3) definitions of some writers and researchers for administrative creativity

\begin{tabular}{|l|l|l|l|}
\hline No. & $\begin{array}{l}\text { Author name and } \\
\text { page number }\end{array}$ & the year & the definition \\
\hline 1 & Daft: 357 & 2001 & $\begin{array}{l}\text { The process of adopting a new idea or behavior on the reality, sector of } \\
\text { work, the organization's market, or its general environment. }\end{array}$ \\
\hline 3 & Al Qasimi : 55 & Satisfaction: 30 & $\begin{array}{l}\text { Ideas and practices presented by managers and employees that aim to find } \\
\text { administrative processes and methods and methods more efficient and } \\
\text { effective in achieving the goals of different organizations, and to be more } \\
\text { service to society. }\end{array}$ \\
\hline 4 & Aziz: 75 & $\begin{array}{l}\text { A deviation from traditional thinking and knowledge, which results in the } \\
\text { discovery of new, developed, acceptable and new ideas, theories, and } \\
\text { methods of work appropriate to the circumstances and capabilities of the } \\
\text { organization, in a manner that helps it to adapt and interact with all } \\
\text { variables, improve its production, and develop its level of performance and } \\
\text { the performance of its employees. }\end{array}$ \\
\hline 5 & Karim: 223 & $\begin{array}{l}\text { The set of processes and behaviors practiced by the individual within the } \\
\text { organization that lead to changes in organizational structures, policies and } \\
\text { administrative patterns through the application of new methods and } \\
\text { methods to solve problems and make decisions in a more authentic way } \\
\text { and in an unfamiliar way. }\end{array}$ \\
\hline
\end{tabular}

\section{Source: The researcher prepared by relying on the sources mentioned in the table}

As a result of the foregoing, administrative creativity can be defined as "a set of ideas, processes and procedures carried out by creative individuals in order to elevate the organization and confront challenges to achieve goals, whether at the individual level, the organization or society in general."

Second: The importance of administrative creativity:

(The Tiger) explains the importance of administrative creativity as follows: (Tiger 62: 1992,)

1- The ability to respond to the changes in the surrounding environment, which makes the organization in a stable position, as it is prepared to face these changes in a way that does not affect the conduct of the regulatory processes.

2- The availability of the administrative creativity feature in the organization helps to develop and improve services in a way that benefits the organization and individuals.

3- Contributing to developing the intellectual and mental capabilities of the workers in the organization by giving them the opportunity to choose those capabilities. 
4- Optimal utilization of financial resources, through the use of practical methods in line with recent developments.

5- The ability to strike a balance between the various development programs and the available material and human capabilities.

6- Good exploitation of human resources, and taking advantage of their capabilities by giving them the opportunity to search for new things in the field of work, and to continuously update work systems in accordance with the surrounding variables.

\section{THE FOURTH TOPIC: PRACTICAL SIDE}

First: View and analyze respondents' responses to leadership styles

\begin{tabular}{|l|l|l|}
\hline Dimensions & Arithmetic mean & standard deviation \\
\hline Authoritarian exploited leadership & 3.35 & 0.65 \\
\hline $\begin{array}{l}\text { Parental Authoritarian } \\
\text { Leadership }\end{array}$ & 3.55 & 0.66 \\
\hline Participating leadership & 3.27 & 0.82 \\
\hline Democratic leadership & 3.59 & 0.49 \\
\hline Democratic leadership & 3.44 & 0.66 \\
\hline
\end{tabular}

1. The results of this table show that there is a relative inclination towards the style of exploited leadership, with an arithmetic mean of (3.35), which is higher than the default mean equal (3) on the scale area, and with a standard deviation of (0.65). It can be said that there is a difference between respondents in determining their agreement with this pattern, and this indicates the existence of an exploitative leadership style that is somewhat tolerable, according to the answers of the research sample.

2. The results of this table show that there is a relative inclination towards the pattern of parental authoritarian leadership, with an arithmetic mean of (3.55), which is higher than the default mean equal (3) to the area of the scale, and with a standard deviation of (0.66). It can be said that there is a difference between respondents in determining their agreement with this pattern This indicates the existence of a dominant patriarchal leadership style in a fairly acceptable degree, according to the answers of the research sample.

3. The results of this table show that there is a relative inclination towards the type of participating leadership, with an arithmetic mean of (3.27), which is higher than the default mean equal (3) on the area of the scale, and with a standard deviation of (0.82). It can be said that there is a difference between respondents in
Table (2) shows the results according to the sample's views on (leadership styles), where table (2) indicates the mean and general standard deviation related to (leadership styles), as the table reflects an overall mean of (3.44), which is higher From the value of the hypothetical mean of (3), which is a good value, and with good harmony in the answers, and confirmed by the value of the standard deviation, as its value reached (0.66) and these results confirm the degree of success of the interest of the research sample on leadership patterns in the ministry, and the total of these results means that the severity of the answers The sample in this axis is heading towards agreement, and the table below shows the arithmetic mean Standard deviation of independent variable dimensions (leadership styles) determining their agreement with this pattern, and this indicates the presence of a leadership style that is fairly acceptable, according to the answers of the research sample.

4. The results of this table show that there is a relative inclination towards the pattern of democratic leadership, with an arithmetic mean of (3.59), which is higher than the default mean equal (3) to the area of the scale, and with a standard deviation of (0.49). It can be said that there is a difference between respondents in determining their agreement with this pattern, and this indicates the existence of a democratic leadership style in a fairly acceptable degree, according to the answers of the research sample.

Second: Presenting and analyzing the respondents' responses to administrative creativity

Table (3) shows the results according to the sample's views on (administrative creativity), where table (3) indicates the mean and general standard deviation related to (administrative creativity), as the table reflects an overall mean of (3.96) which is higher than The value of the hypothetical mean of (3), which is a good value, and with good harmony in the answers, and confirmed by the value of the standard deviation, as its value reached $(0.55)$ and these results confirm the degree of success of the interest of the research sample 
about administrative creativity in the ministry, and the total of these results means that the severity of the sample answers This axis is oriented towards agreement, and the table below shows the arithmetic

Table (3) shows the arithmetic mean and the standard deviation of the dimensions of the dependent variable (administrative innovation).

\begin{tabular}{|l|l|l|}
\hline Dimensions & Arithmetic mean & standard deviation \\
\hline Administrative leadership & 4.25 & 0.46 \\
\hline Strategic thinking & 3.44 & 0.75 \\
\hline The ability to analyze & 3.67 & 0.66 \\
\hline Change & 3.90 & 0.51 \\
\hline Taking the risk & 4.02 & 0.45 \\
\hline Stimulus & 3.93 & 0.46 \\
\hline administration creativity & 3.96 & 0.55 \\
\hline
\end{tabular}

A. Administrative leadership: The weighted mean of the administrative leadership reached (4.25) and a standard deviation (0.46), and since the hypothetical mean was (3) on the area of the scale, this indicates a noticeable progress towards administrative leadership, and this indicates that managers, as administrative leaders, can contribute to Developing the creative abilities of their subordinates by raising their morale and cultivating a spirit of positive competition between them.

B. Strategic thinking: The weighted mean reached (3.98) and with a standard deviation (0.75), and since the hypothetical mean was (3) on the scale of the scale, this indicates a noticeable progress towards the strategic thinking factor, and this indicates the availability of capabilities and skills necessary to carry out future forecasts, with the possibility Formulating strategies and taking decisions adapted to the nature of the Ministry's work to win the most competitive positions in light of its limited resources.

C. The ability to analyze: The weighted mean has reached (3.67) with a standard deviation (0.66), and since the hypothetical mean is (3) on the area of the scale, this indicates a noticeable progress towards the factor of the ability to analyze, and this indicates the existence of administrative capabilities that have capabilities On analysis as a mental level associated with distinct analysis while performing tasks.

D. The change: The weighted mean of this factor reached (3.90) and with a standard deviation (0.51), and since the hypothetical mean was (3) on the scale of the scale, this indicates a noticeable progress towards the change factor, and this indicates that the Ministry's administration seeks to develop and keep abreast of all modern conditions. Through the processes of change and the constant search for everything that would achieve more efficiency and effectiveness. and grammatical circles Raph normative for the dimensions of the dependent variable (administrative innovation).
H. The risk: The weighted mean (4.02) and the standard deviation (0.45) and the hypothetical mean were (3) on the area of the scale, this indicates a noticeable progress towards the risk factor, and this indicates the ability of the Ministry's administration to tighten control and control of the risks facing its activities. And its work, and its ability to reduce losses and explain them to the minimum possible and determine the actions and actions that must be taken in relation to specific risks to control events and control losses.

f. Motivation: The weighted mean of this factor reached (3.93) with a standard deviation (0.47), and since the hypothetical mean is (3) on the area of the scale, this indicates a noticeable direction of a factor Motivation, and this indicates the importance of motivation in the ministry and its role as one of the factors affecting the behavior of working individuals and raising the efficiency of their job performance and pushing them towards achieving the goals of the organization.

\section{Third: testing the research hypotheses}

1- The first main hypothesis: There is a correlation between leadership styles and administrative creativity in the Ministry of Education.

In order to make a decision on the first major hypothesis, which consists of four sub-assumptions for both the exploitative leadership, the patriarchy, the participatory leadership, the democratic leadership, the Pearson correlation coefficient between each dimension of leadership patterns and administrative creativity will be calculated through the Ready Statistical Program (SPSS) as well. In Table 4, the results are interpreted as follows:

Table (4) represents the correlation coefficients between the dimensions of leadership patterns and administrative creativity 


\begin{tabular}{|l|l|l|l|l|}
\hline $\begin{array}{l}\text { Driving leadership styles } \\
\text { administration creativity }\end{array}$ & $\begin{array}{l}\text { Authoritarian } \\
\text { exploited } \\
\text { leadership }\end{array}$ & $\begin{array}{l}\text { Parental } \\
\text { Authoritarian } \\
\text { Leadership }\end{array}$ & $\begin{array}{l}\text { Participating } \\
\text { leadership }\end{array}$ & $\begin{array}{l}\text { Democratic } \\
\text { leadership }\end{array}$ \\
\hline $\begin{array}{l}\text { Pearson correlation } \\
\text { coefficient }\end{array}$ & 0.679 & 0.546 & 0.357 & 0.578 \\
\hline Sig & 0.000 & 0.000 & 0.011 & 0.000 \\
\hline
\end{tabular}

1. We note that the value of the Pearson correlation coefficient indicates after the exploitative leadership exploited and administrative creativity is (0.679) which is a positive positive value with a statistical significance at the level of significance $(0.05)$ and thus the first sub hypothesis is accepted which states "There is a correlation relationship between the exploitative and exploitative leadership used In the Ministry of Education and Administrative Creativity. "

2. We note that the value of the Pearson correlation coefficient is constructed after parental exploiting leadership and administrative creativity is (0.596) which is a positive positive value with a statistical significance at the level of significance $(0.05)$ and thus the second sub-hypothesis is accepted which states "There is a correlation relationship between the authoritarian parental leadership used In the Ministry of Education and Administrative Creativity. "

3. We note that the value of the Pearson correlation coefficient indicates after the participating leadership and administrative creativity is (0.357), which is a positive positive value with a statistical significance at the level of significance (0.05) and thus the third sub hypothesis is accepted, which states "There is a correlation relationship between the participating leadership used in a ministry Education and administrative creativity. "

4. We note that the value of the Pearson correlation coefficient is built after the democratic leadership and administrative creativity is $(0.578)$, which is a positive positive value with a statistical significance at the level of significance (0.05) and thus is Accepting the fourth sub-hypothesis, which states "There is a correlation between the democratic leadership used in the Ministry of Education and administrative creativity."

As a result of accepting the four sub-hypotheses that are concerned with leadership styles, the first general hypothesis is accepted, which states "There is a correlation between leadership styles and administrative creativity in the Ministry of Education." 2- The second main hypothesis: There is an influential relationship of significant statistical significance between the leadership styles represented (leadership, patriarchy, participation and democracy) in the Ministry of Education and Administrative Creativity.

In order to make a decision on the second main hypothesis, which consists of four sub-assumptions for both the exploited dominant leadership, the patriarchal dominant leadership, the participatory leadership, the democratic leadership the moral effect will be calculated using the multiple regression model where the variables (dominant exploitative leadership, patriarchal leadership, leadership Participation, democratic leadership) are independent variables and administrative creativity is an approved variable using the SPSS program as in Table (5) the following:

Table (5) Results of transaction values used in measuring the impact of leadership patterns and administrative innovation

\begin{tabular}{|l|l|l|l|l|l|}
\hline $\mathrm{y}$ & $\mathrm{x}$ & $\mathrm{P}_{-}$Value & Ttab & Tcal & Adjusted $^{2}$ \\
\hline $\begin{array}{l}\text { administration } \\
\text { creativity }\end{array}$ & $\begin{array}{l}\text { Authoritarian exploited } \\
\text { leadership }\end{array}$ & 0.000 & 1.671 & 11.859 & 0.03 \\
\hline & $\begin{array}{l}\text { Parental Authoritarian } \\
\text { Leadership }\end{array}$ & 0.000 & 1.671 & 10.507 & 0.19 \\
\hline & $\begin{array}{l}\text { Participating leadership } \\
\text { Democratic leadership }\end{array}$ & 0.000 & 1.671 & 16.312 & 0.02 \\
\hline
\end{tabular}

1. Table (5) showed that there is a statistically significant effect at the level of significance (0.05) of the exploited driving axis dominated in the administrative creativity variable because the calculated value of $(\mathrm{t})$ is equal to (11.859) which is greater than its tabular counterpart equal to (1.671) while interpreting The independent variable, the exploited leadership, which is $(3 \%)$ of the total 
deviations in the values of administrative creativity, which is reflected in the value of the determination coefficient, as the value of the regression parameter will be statistically significant.

Thus, the estimated regression equation for the influence of the exploited driving axis dominating the administrative creativity variable is as follows:

$\mathbf{y}=\mathbf{a}+\mathbf{b x}$

Administrative creativity $=3.886+(0.022)$ exploitative leadership

The equation means that an increase in the exploited driving variable by one unit is offset by an increase in administrative creativity of (0.022). By this we accept the first sub-hypothesis, which states, "There is an influence relationship with significant statistical significance between the exploitative and authoritarian leadership used in the Ministry of Education and administrative creativity."

2. Table (5) showed that there is a statistically significant effect at the level of significance (0.05) of the parental dominant leadership axis in the administrative creativity variable because the calculated value of $(t)$ is equal to (10.507) which is greater than its tabular counterpart equal to (1.671) while interpreting The independent variable, the exploiting leadership, which dominated (19\%) of the total deviations in the values of administrative creativity, which was reflected by the value of the determination parameter, as the value of the regression parameter would be statistically significant.

Thus, the estimated regression equation for the influence of the authoritarian parental leadership axis in the variable of administrative creativity is as follows:

$\mathbf{y}=\mathbf{a}+\mathbf{b} \mathbf{x}$

Administrative creativity $=3.527+(0.122)$ parental authoritarian leadership

The equation means that an increase in the parental authority leadership variable by one unit is offset by an increase in administrative creativity of $(0.122)$. By this we accept the second sub-hypothesis, which states, "There is an influential relationship of significant statistical significance between the authoritarian and patriarchal leadership used in the Ministry of Education and administrative creativity."

3. Table (5) showed a statistically significant effect at the level of significance (0.05) of the driving axis involved in the variable of administrative creativity because the calculated value of $(\mathrm{t})$ is equal to (16.312) which is greater than its tabular counterpart equal to (1.671) while the variable is explained Independent
Participating Leadership (2\%) of the total deviations in the values of administrative creativity, which is reflected in the value of the determination coefficient, as the value of the regression parameter will be statistically significant.

Thus, the estimated regression equation for the influence of the driving axis involved in the variable of administrative creativity is as follows:

$\mathbf{y}=\mathbf{a}+\mathbf{b} \mathbf{x}$

Administrative Creativity $=4.192-$

Participatory Leadership

The equation means that a decrease in the participating leadership variable by one unit is offset by a decrease in administrative creativity of (0.071). By this we accept the third sub-hypothesis, which states, "There is an effective relationship of significant statistical significance between the participating leadership used in the Ministry of Education and Administrative Innovation."

4. Table (5) showed that there is a statistically significant effect at the level of significance $(0.05)$ of the axis of democratic leadership in the variable of administrative creativity because the calculated value of $(t)$ is equal to (6.855) which is greater than its tabular counterpart equal to (1.671) while interpreting the variable Independent Democratic leadership represented $(82 \%)$ of the total deviations in the values of administrative creativity, which was reflected by the value of the determination coefficient, as the value of the regression parameter will be statistically significant.

Thus, the estimated regression equation for the influence of the democratic leadership axis on the variable of administrative creativity is as follows:

$\mathbf{y}=\mathbf{a}+\mathbf{b x}$

Administrative innovation $=3.057+(0.251)$ democratic leadership

The equation means that an increase in the democratic leadership variable by one unit is offset by an increase in administrative creativity of (0.251). By this we accept the fourth sub-hypothesis, which states, "There is an effective relationship of significant statistical significance between the democratic leadership used in the Ministry of Education and Administrative Innovation."

\section{THE FIFTH TOPIC: CONCLUSIONS AND RECOMMENDATIONS}

First: Conclusions

1. The concept of an exploitative leadership style that essentially dominates and underscores the phenomenon 
of unilateral hegemony in the decision-making process, setting policies and identifying aspects of activities or technical and administrative activities.For individuals, dealing with them on the basis of individual rather than collective tendency, as he supervises in detail the instructions and formulas for their implementation.

2. Parental, authoritarian leadership style depends mainly on regulations and laws, and sometimes accepts the subordinates 'opinion to solve work problems, and the leader sets an action plan and how it should be implemented in which all workers are required to have certain levels of performance, poor channels and content of communication between individuals, irregularity, and the emergence of negative spirit phenomena and rumors Non-commitment and nonpurposeful communication. And the leader's limited confidence in the subordinates explicitly. And using it from his official authority is a tool of governance and pressure on their subordinates who do not compel them to complete the work, and resort to threats and punishment to achieve the achievement, in addition to that, the organizational climate does not encourage subordinates to speak freely with their superiors about their issues and problems within the organization. However, this pattern provides speed in operation and clear direction. If the leader leaves a position that leads to the dissolution of the group and a decrease in morale.

3. Through the conceptual framework of the research, the style of participating leadership was characterized by the availability of great confidence between the leaders and their subordinates, focus on the collective goal and the work of the one team, the subordinates' sense of freedom to discuss and involve them in the decision-making process to solve work problems, evaluate their performance, and encourage them to use their technical skills in the organization, And create a positive healthy regulatory environment, to raise the morale of individuals to achieve job satisfaction for them and achieve the goals of the organization.

4. The democratic leadership style is characterized by granting the full confidence of the followers and the collective participation, and ensuring that they are consulted before making the decision, and delegating them with routine matters, and the feeling of workers with complete freedom to discuss issues, express opinions and proposals, enhance two-way communication, deepen the objectivity of evaluating and motivating the performance of employees, as well as raising levels of performance and support Efforts of continuous improvement, organizational development and total quality management that are important and fundamental factors in administrative creativity.

5. The Ministry of Education gives the opportunity and contribution to the feminist component in leadership or management and at various levels, and this gives an indication to the ministry in question by taking into account the characteristics that women generally distinguish when developing leadership training programs, and this enhances the endeavor of the research organization, in Spreading the philosophy of participatory leadership style and democratic leadership style, as this leadership style mainly has accumulated experiences in the educational and administrative field.

6. That dealing with subordinates within the researched organization is not based on forcing their subordinates to do the work and is not based on individual, hostile, and not collective tendency among members of the organization, this leads to low morale, weak social cohesion, high complaints from members, and a high rate Work turnover. Weak ties of affection and love among the members of the organization .

7. The researched organization does not tend to follow the practices of patriarchal authoritarian leadership when dealing with subordinates within the organization, as it does not believe in using the method of pressure, intensity, and control of subordinates without the leader's respect for his subordinates, which results in generating a sense of failure and hatred for the work environment and not using threat and punishment to achieve achievement, Which leads to negative phenomena of the soul, the spread of noncompliant tendency and non-purposeful communication.

8. It became clear through the results of the analysis that there is a significant correlation relationship between the independent variable (leadership patterns) and its dimensions with the dependent variable (administrative creativity) in line with what was included in the first main hypothesis and the validity of its test.

\section{Second: Recommendations}

The introduction of individuals working in specific courses to consolidate the concepts of creativity in them and embody them through them as upward practices at the level of career behavior.

Activating the system of rewards and incentives in a way that brings workers to a high level of performance based on the equivalent levels of satisfaction.

Create a climate characterized by a high ability to remove organizational obstacles that affect the release of creative energies for workers in a manner that 
contributes to creating an encouraging environment for all that is new in the areas of administrative and educational work.

Adopting a culture of partnership and participation to raise the ability of workers to bear the responsibilities and decisions taken by them, which confirm the extent of their commitment and commitment to all behavioral practices issued in the workplace, leading to the embodiment of belonging and loyalty.

The delegation of powers by the higher management of workers at all levels of their administration in a way that encourages individual entrepreneurship and responsibility and the ability to make decisions freely according to the requirements of the situation

6. The necessity of the Ministry of Education to pay attention to the two patterns of leadership (participation and democracy), encouraging, promoting and developing them among the decision makers in them through the requirements of their application, which were mentioned in the questionnaire expressions, especially since field research results have shown the high level of these two patterns referred to above. Therefore, if the ministry wants to achieve benefit from it and support educational performance through influential relationships with the dimensions of administrative creativity, in a way that ensures that it is properly invested.

7. Adopting the pattern or behavior of democratic leadership by leaders, because this behavior, as studies in this field have shown, as well as what has been found in the current research, has a great role in stimulating, empowering and encouraging subordinates and raising them, and generating a sense of them that they play important roles in the organization, which necessitates them. Make additional intellectual and practical efforts that go beyond mere routine work.

8. Rewarding the pattern or behavior of the administrative leadership by focusing on the extent to which employees engage in such behavior, as well as the official work duties assigned to them. And that incentive schemes established tend to relate to awarding rewards to the group or team, and not at the individual level with caution against rewarding workers who engage in non-cooperative and unconstructive competitive behaviors that do not match the style of participatory leadership and the pattern of democratic leadership.

\section{REFERENCES}

1. Haider, Haider Ali, (2009), The prevailing leadership patterns among middle school principals from the viewpoint of faculty members, Journal of Educational and Psychological Research, No. 26 and 27, College of Education - AlMustansiriya University.

2. Khasawneh, AkefLutfi, (2011), Creative Management in Business Organizations, First Edition, Dar Al-Hamid for Publishing and Distribution - Amman

3. Dora, Abdul Bari, Al-Madhoun, Musa, and Al-Jazrawi, Ibrahim (1994), Modern Management, Concepts and Operations, Scientific Analytical Method, First Edition, Arab Center for Student Services - Amman.

4. Reda, Hatem Ali Hassan, (2003). "Administrative creativity and relationships with job performance. An applied study on the security services at King Abdulaziz International Airport in Jeddah." Master Thesis, College of Scientific Studies, Naif Arab University for Security Sciences, Riyadh, Saudi Arabia.

5. Al-Sharif, Talal Abdul-Malik, (2004), leadership styles and their relationship to job performance from the viewpoint of workers in the Principality of Makkah Al-Mukarramah, published Master's degree in Administrative Sciences published, Naif Arab University for Security Sciences - Riyadh.

6. Al-Taie, Rana Nasser Sabr, (2007), Leadership Styles and Organizational Confidence and its Impact on Achieving Organizational Commitment: An Empirical Study of the Views of a Sample of Managers in Mixed Industrial Sector Companies, Unpublished Master of Business Administration Thesis, College of Administration and Economics University of Baghdad.

7. Abdullah, Nahida Ismail, and Abdul Razzaq, Omar Muhammad Subhi, (2009), The Impact of the Leadership Style on Building the Organization's Strategic Capabilities: An Analytical Study of Managers 'Views on a Sample of Industrial Organizations in Nineveh Governorate, Al-Rafidain Development Magazine, Volume 31, No. 93 , College of Administration and Economics - University of Mosul.

8. Aziz, Delman Ahmed, (2011), "Empowerment and its role in administrative creativity: a study of the views of administrative leaders of private commercial banks in the city of Sulaymaniyah," Master of Business Administration, College of Administration and Economics, University of Sulaymaniyah, Iraq. 
9. Al-Aibani, Zayed Bin Fahd, (2011), Leadership Styles and Their Relationship with the Methods of Organizational Conflict Management in the Emergency Force for Riyadh Region, Master Thesis in Administrative Sciences published, Naif Arab University for Security Sciences - Riyadh.

10. Al-Qasimi, OmaimaBint Abdul Aziz, (2002), "The Concept of Administrative Creativity and Development". One of the corridors of the work of the Third Arab Conference in Administration: Creative Leadership and Innovation in the Light of Integrity and Transparency, Office of the Minister of State for Administrative Development _ The Republic of Lebanon, in partnership with the Arab Organization For Administrative Development, Beirut, League of Arab States. 